\title{
A VIOLÊNCIA SEXUAL INTRAFAMILIAR CONTRA CRIANÇAS E ADOLESCENTES E O TRABALHO PROFISSIONAL DO ASSISTENTE SOCIAL
}

Intra-Family Sexual Violence against Children and Adolescents and the Professional Work of Social Workers

\author{
Mayara Simon Bezerra, Maria Cristina Piana, Adriana Giaqueto Jacinto
}

Universidade Estadual Paulista, Brasil

KEY WORDS

Social Work

Professional Work

Sexual Violence

Child and Teenager
ABSTRACT

Violence is something that is becoming more and more present in the history of society. One of the types that it presents is intrafamily sexual violence against children and adolescents, committed by those who would have the function of protecting them against any and all forms of violence. Acting directly with the child and adolescent who are victims of this violation and their family members, the social worker seeks the realization of rights, the reflection that everyone is a subject of rights, protagonists of their history. It carries out referrals and interventions that seek to strengthen the family and "overcome the situation of violence".

RESUMEN

A violência é algo que está se tornando cada vez mais presente na história da sociedade. Uma das formas apresentadas é a violência sexual intrafamiliar contra crianças e adolescentes, cometida por aqueles que teriam a função de protegê-los contra toda e qualquer forma de violência. Atuando diretamente com a criança e o adolescente, vítimas desta violação, e seus familiares, o assistente social busca a efetivação dos direitos, a reflexão de que todos são sujeitos de direitos, protagonistas de sua história. Realiza encaminhamentos e intervenções que buscam fortalecer a família e "superar a situação de violência".

Recibido: 30/04/2020

Aceptado: 08/10/2020

\section{GLOBAL KNOWLEDGE}




\section{Introdução}

A violência sexual contra crianças e adolescentes está presente em todo o mundo, dentro e fora dos lares, crescendo a cada dia, e na maior parte dos casos, encoberta por um pacto de silêncio.

Praticada dentro dos lares, é conhecida como violência sexual intrafamiliar, sendo cometida por aqueles que deveriam zelar e proteger os direitos de crianças e adolescentes.

Neste trabalho, discorremos sobre esta modalidade de violência contra crianças e adolescentes, apresentando seu conceito e o trabalho do Assistente Social ${ }^{1}$, profissional que realiza atendimento a estes casos. A reflexão apresentada é resultado de pesquisa bibliográfica e de campo aprovada pelo Comitê de Ética em Pesquisa da Faculdade de Ciências Humanas e Sociais - UNESP Campus de FrancaSP/Brasil sob o parecer no 380.54/2013, em uma cidade do interior do Estado de São Paulo (SP).

$\mathrm{Na}$ primeira parte, apresentamos uma reflexão e alguns dados sobre a violência sexual no Brasil e na modalidade intrafamiliar e, posteriormente, sobre o trabalho profissional do assistente social, especificamente nos casos de violência sexual intrafamiliar contra crianças e adolescentes.

\section{Violência sexual intrafamiliar contra crianças e adolescentes}

A violência sexual contra crianças e adolescentes pode ser definida como "[...] atividades sexuais inapropriadas para a idade e o desenvolvimento psicossexual de crianças e adolescentes. Pode ocorrer por meio de sedução, ameaça, chantagem

\footnotetext{
10 Serviço Social surge no Brasil na década de 1930, com o referencial da corrente europeia e se expande pelo país a partir de 1945. A profissão é regulamentada pela Lei no 8.662 de 07 de junho de 1993, que dispõe sobre o exercício profissional, bem como suas competências e atribuições privativas. O Código de Ética 1993 reafirma para a profissão os princípios éticos como a liberdade e o comprometimento com a autonomia e com emancipação plena do indivíduo e o compromisso com outra sociabilidade que não se paute na exploração/opressão de classe, etnia e gênero. A organização do Serviço Social abrange todo o conjunto compreendido entre o Conselho Federal de Serviço Social (CFESS), Conselhos Regionais de Serviço Social (CRESS), a Associação Brasileira de Ensino e Pesquisa em Serviço Social (ABEPSS) e a Executiva Nacional de estudantes de Serviço Social (ENESSO), além de sindicatos e associações.
}

ou força" (Graciani et al., 2013, p.49). Essa violência pode ser considerada uma das formas mais cruéis de violação aos direitos fundamentais da criança e do adolescente, assim como, aos direitos humanos.

É uma relação em que o adulto obriga a criança e/ou adolescente a realizar atos de caráter sexual para sua satisfação própria ou de outros, mediante uma relação desigual de força, poder e violência psicológica, sob constante ameaça.

Nestes casos, em sua maior parte, a violência sexual vem acompanhada da violência física e violência psicológica, além de castigos físicos como punição e forma de controle e poder, bem como uma constante ameaça psicológica, que abala o emocional da criança e do adolescente, fazendo-os sentir medo de denunciar o fato, com ameaças a familiares e/ou pessoas próximas, culpando-os pelo que pode acontecer, além de colocar que sua palavra sobre o fato vai ser desacreditada. Destacase que este é um dos fatores que contribuem para a não denúncia dos casos:

Estima-se que poucos casos são denunciados.
Quando há envolvimento de familiares, existem
poucas probabilidades de que a vítima faça a
denúncia, seja por motivos afetivos, seja por
medo: do abusador; de perder os pais; de ser
expulso; de que outros membros da família não
acreditem em sua história; ou de ser o
causador da discórdia familiar. (Santos,
Ippolito, 2009, p. 35)

No Brasil, as legislações consideram crime o ato sexual praticado por maiores de 18 anos de idade contra menores de 14 anos, sob pena de reclusão de 8 a 15 anos. No que diz respeito à proteção de crianças e adolescentes, o país possui o Estatuto da Criança e do Adolescente (ECA), que garante a proteção integral de crianças e adolescentes e os reconhece como sujeitos de todos os direitos inerentes à pessoa humana (Brasil, 2015).

Mesmo com a proteção que o Estatuto garante, milhares de crianças brasileiras ainda são vítimas da violência todos os dias. Dados do Anuário Brasileiro de Segurança Pública (Bueno, Lima, p.07, 2019) revelam que foram registrados 66.041 casos de violência sexual no Brasil, em 2018, dos quais 53,8\% das vítimas tinham até 13 anos de idade, revelando ainda que 04 meninas de até 13 anos são estupradas por hora no país. 
Os dados são assustadores e trazem para a visão pública que crianças e adolescentes são vítimas da violência sexual todos os dias no país, tendo todos os seus direitos negados, comprometendo seu desenvolvimento emocional, físico e psicossocial.

Como uma das formas de incentivar a denúncia de violações de direitos contra crianças e adolescentes, o Brasil possui o Disque 100 Disque Direitos Humanos, que está vinculado ao Ministério da Mulher, da Família e dos Direitos Humanos, do Governo Federal.

O Disque 100 é um canal de denúncias contra violações aos direitos humanos, funcionando todos os dias da semana, sem interrupção. Por meio de ligação gratuita e anônima, é possível denunciar casos de violações contra população em situação de rua, crianças e adolescentes, pessoas com deficiência, pessoa idosa, igualdade racial, pessoas em restrição de liberdade, LGBT (Lésbicas, Gays, Bissexuais, Travestis, Transexuais ou Transgêneros) e outros. Após a denúncia ser recebida, é encaminhada aos órgãos de proteção e atendimento para serem verificadas e tomadas as medidas cabíveis de proteção contra a denúncia de violação recebida.

O gráfico a seguir apresenta uma comparação das denúncias de violações de direitos contra crianças e adolescentes no Brasil, incluindo a negligência, violência psicológica, violência física, violência sexual e outras violações, também as denúncias referentes à violência sexual, recebidas pelo Disque 100 nos anos de 2016 e 2017 em todo território nacional.

Figura 1.

Comparativo de Denúncias Criança e Adolescente entre 2016 e 2017.

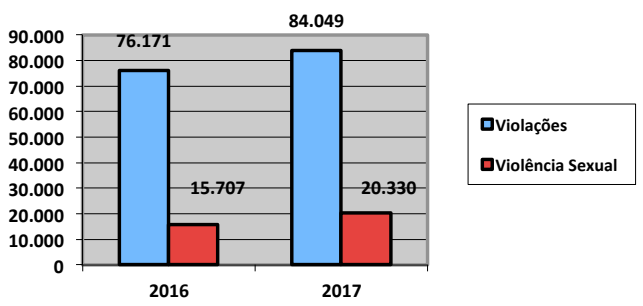

Fonte: Brasil, 2019.

Depreende-se, assim, que houve um aumento no número de denúncias em relação ao ano de
2016 para 2017, e o mesmo acontece nas denúncias de violência sexual.

Em relação ao número de denúncias, vale ressaltar que estas podem ir muito mais além dos números que aparecem nas estatísticas oficiais, visto que nem todos os casos são denunciados ou chegam aos órgãos de atendimento, portanto os casos que aparecem nas estatísticas são apenas a ponta do iceberg, o que se vê, mas lá no fundo, embaixo, está o contingente de vítimas que vivem sob o medo, ameaça e sendo abusadas. Conforme divulgado pela Childhood Brasil (2019) "Estima-se que apenas $10 \%$ dos casos de abuso e exploração sexual contra crianças e adolescentes sejam, de fato, notificados às autoridades".

A subnotificação dos casos de abuso sexual contra crianças e adolescentes é algo presente no mundo todo, envolvendo uma gama de fatores:

A violência sexual ocorre no mundo todo e, por conta de sua complexidade, faltam dados internacionais e nacionais capazes de medir, com precisão, esse fenômeno. De modo geral, os crimes sexuais cometidos contra crianças e adolescentes estão cercados por preconceitos, tabus, pelo silêncio e, por esse motivo, muitas vezes sequer são denunciados. Daí, a dificuldade de haver números consolidados e detalhados sobre o problema, tanto no Brasil quanto em todo o mundo. (Santos, Ippolito, 2009, p. 31).

Quando essa violência acontece dentro do ambiente familiar, é denominada violência sexual intrafamiliar, ou seja, é aquela que acontece na esfera do lar, dentro de casa, em que o abusador é um familiar ou alguém que tem uma relação de confiança com a vítima e sua família, exercendo poder sobre ela, como pais, padrastos, madrastas, tios, irmãos, avós, amigos próximos, dentre outros. Nestes casos a violência é mantida em um pacto de silêncio, cercado de segredos e ameaças:

No complô do silêncio, tudo o que acontece dentro do lar é envolvido num pacto de silêncio familiar; o abuso é mantido em segredo e, algumas vezes, encoberto por outros membros da família, em que o abusador, por deter o poder moral e econômico, faz com que o fato seja mantido em segredo. A prática do abuso pode durar e se repetir por meses ou até anos, ficando, muitas vezes, na impunidade. (Piana, Bezerra, 2019, p. 205). 
Os casos de violência sexual intrafamiliar são difíceis de serem identificados, visto que são reforçados pelo pacto de silêncio que ronda e permanece no ambiente familiar, perpetuando esta violação e fazendo com que continue a acontecer, sob constante ameaça e violência psicológica. Gabel (1997, p. 11) destaca que "O abuso praticado contra a criança é uma das formas de maus-tratos que mais se ocultam: a criança tem medo de falar e, quando o faz, o adulto tem medo de ouvi-la."

A prática do abuso pode durar e se repetir por meses ou até anos, ficando, muitas vezes, na impunidade decorrentes do sentimento de medo, raiva, ódio, ameaças.

Algumas crianças e adolescentes começam a ser vitimizados muito pequenos no âmbito do lar, permanecendo tudo o que ocorre dentro do pacto de silêncio familiar, em que o abuso é mantido em segredo, e algumas vezes, conivente por outros membros da família, onde o abusador, por deter, muitas vezes, o poder moral e econômico, faz com que o fato seja mantido em segredo. "Na violência sexual intrafamiliar o ambiente familiar pode se tornar um cárcere privado, em que a criança, não sabe quanto tempo a violação vai durar e quando ela poderá sair deste ambiente" (Piana, Bezerra, 2019, p. 205).

Na pesquisa realizada, no ano de 2013, numa cidade da região nordeste do Estado de São Paulo (Brasil), em que foram analisados 19 casos de violência sexual contra crianças e adolescentes, verificou-se que conforme as estatísticas, a maior parte dos casos é cometida por alguém conhecido:

Figura 2.

Parentesco do agressor com a vítima

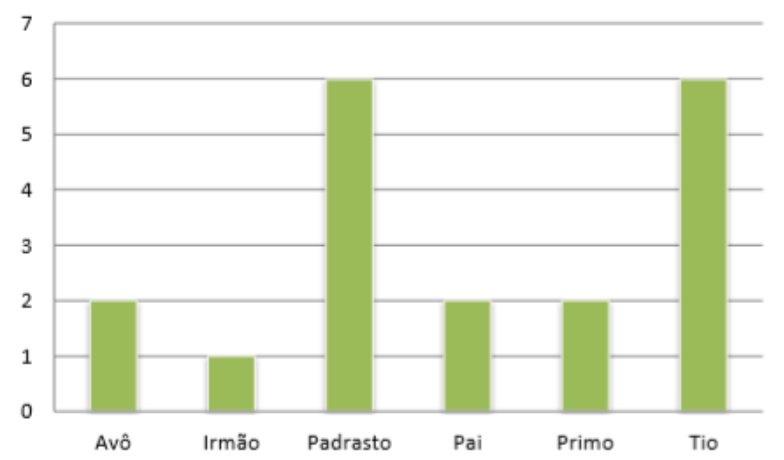

Fonte: Bezerra, M.S. 2013.
Segundo a mesma pesquisa, verifica-se mais uma vez que as crianças são as maiores vítimas da violência sexual:

Figura 3.

Faixa etária das vítimas

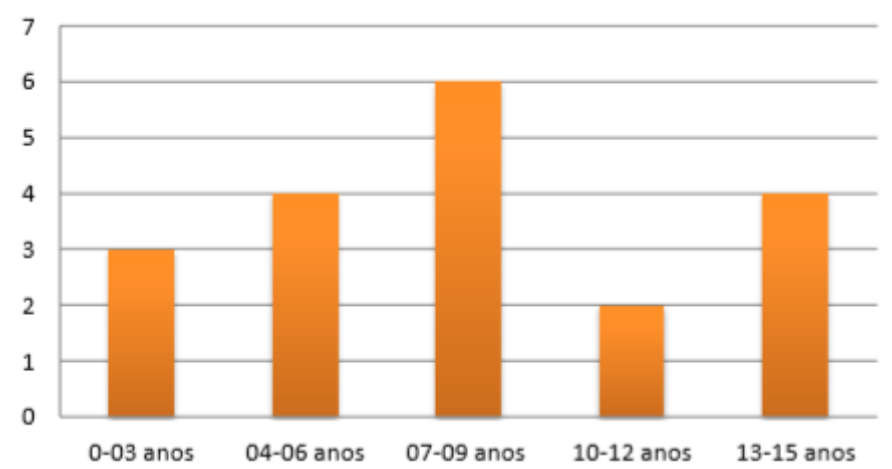

Fonte: Bezerra, M.S. 2013.

Observa-se que das $78,9 \%$ das vítimas são crianças de até 12 anos de idade e que, desde cedo, já começam a serem violentadas, conforme se pode observar na faixa etária de 0 a 3 anos.

Os dados apresentados demostram que a violência sexual pode acontecer desde muito cedo e que crianças e adolescentes são violentados sexualmente dentro de casa, no âmbito familiar por alguém que teria o dever de garantir e proteger seus direitos; ficando a mercê da própria sorte, esperam que a violação seja descoberta por alguém para que possam sair do pesadelo e crueldade, que é a violência sexual.

Quando o caso é descoberto ou denunciado, a criança é inserida nos serviços de atendimento e proteção, sendo atendida por diversos profissionais, dentre eles o/a Assistente Social, como veremos a seguir.

\section{A violência sexual intrafamiliar e o trabalho profissional do assistente social}

0 assistente social tem como objeto de seu trabalho profissional a questão social, e realiza seu trabalho junto aos mais diversos segmentos da classe trabalhadora. A questão social pode ser compreendida como a contradição existente entre capital - trabalho, as desigualdades da sociedade capitalista, em que a riqueza socialmente produzida fica com uma pequena parte da população. Os assistentes sociais 
trabalham com a questão social nas suas mais variadas expressões quotidianas, tais como os indivíduos as experimentam no trabalho, na família, na área habitacional, na saúde, na assistência social pública etc.

Questão social que, sendo desigualdade é também rebeldia, por envolver sujeitos que vivenciam as desigualdades e a ela resistem e se opõem. É nesta tensão entre produção da desigualdade e produção da rebeldia $e$ da resistência, que trabalham os assistentes sociais, situados nesse terreno movidos por interesses sociais distintos, aos quais não é possível abstrair ou deles fugir porque tecem a vida em sociedade (Iamamoto, 2012, p.28, grifo da autora).

A partir da questão social, a necessidade de políticas sociais começa a ficar cada vez mais evidente e desta forma o Estado passa a intervir na esfera da vida social, tratando-a como um problema social, demandando o trabalho do assistente social, que atua diretamente na esfera pública ou privada. Juntamente com as políticas sociais, os sistemas de proteção social passam a ser respostas fragmentadas às expressões da questão social.

A questão social, em suas múltiplas expressões, demanda o trabalho profissional do assistente social, seja através da criança e adolescente vítimas de violência, pessoa idosa, trabalho infantil, violência contra a mulher, relações de gênero, luta por moradia e condições dignas de sobrevivência, dentre outras expressões que se refletem na vida cotidiana, devendo o profissional compreender como os indivíduos vivenciam, absorvem essas expressões.

Desse modo, é de suma importância que o assistente social conheça, pesquise a realidade na qual está inserido e exerce seu trabalho, as diversas faces da questão social e a realidade em que ela se apresenta. 0 conhecimento se torna ferramenta indispensável do trabalho profissional, exigindo do assistente social a apreensão das diversas manifestações da questão social nos níveis em que ela se apresenta, seja estadual, regional ou municipal, sendo fundamental na atuação profissional, para assim saber qual será a direção a seguir.

Destaca-se aqui um ponto importante: a violência em que as pessoas estão submetidas em seu cotidiano. A questão social, através de suas expressões, marca a vida das pessoas, gerando uma série de fatores, as pessoas passam a ficar expostas a todo tipo de violência, inclusive por parte do poder público, lugar em que deveriam encontrar as bases para superação destas. Até mesmo as crianças e adolescentes vítimas de violência sexual intrafamiliar, nos locais em que passam por atendimento, além de terem que relatar o que aconteceu a outras pessoas, ocorre muitas vezes o fato de não acreditarem no que dizem, de pensarem que é algo que "inventaram" para prejudicar aquele familiar. Algumas vezes o próprio local da denúncia e atendimento pode significar uma violência novamente.

Neste contexto, o trabalho profissional do assistente social precisa estar em consonância e acompanhar as mudanças societárias na medida em que as transformações no mundo do trabalho e a acumulação vigente se modificam, estando atendo para as novas manifestações da velha questão social que se apresenta com uma nova roupagem, rebatendo diretamente na vida dos indivíduos. Deparamo-nos aqui, novamente, com a importância, por parte do profissional, de conhecer a realidade e as novas manifestações pela qual a questão social se apresenta e seus rebatimentos na vida das pessoas que demandam pelo seu trabalho.

Por meio de seu trabalho, o assistente social tem a capacidade de transformar a realidade em que está inserido, sendo esta transformação o produto de seu trabalho. Atua diretamente na esfera da produção e reprodução social, no qual a questão social com todas suas expressões e desigualdades advindas do sistema capitalista demandam a intervenção do assistente social e um "controle" por parte do Estado a fim de minimizar seus reflexos e controlar a população, através de políticas sociais focalizadas e cada vez mais seletivas, em que somente "o pobre do mais pobre" é quem pode ter acesso aos benefícios e serviços oferecidos.

0 assistente social passa a atuar neste campo repleto de tensões, no qual o Estado o requisita para controlar as reinvindicações trazidas pela grande parcela da população que necessita destes serviços. Cabe ao assistente social assumir sua posição política em defesa da classe 
trabalhadora, aliado ao Código de Ética Profissional e apropriando-se do Projeto Ético Profissional, que visa a liberdade como valor central e a emancipação humana.

Através de suas competências teóricometodológica, técnico-operativa e ético-política, articuladas entre si, o profissional pode ter uma atuação voltada a um viés mais crítico, indo além do que lhe é dado, desvelando a realidade aparente, além de sua aparência e descobrindo a essência do real. (Kosik, 1976, p. 18). 0 trabalho do assistente social tem que ser pensado na perspectiva de totalidade, entendendo como a centralidade do trabalho determina as condições da vida social e as relações que se estabelecem por meio deste.

É preciso aprender a pensar dialeticamente, ir além da aparência, da imediaticidade, pois assim a intervenção será completa, captando as mediações existentes, sendo o conhecimento, instrumento fundamental ao assistente social, conhecimento este que tem que ser aprofundado o tempo todo.

Diante das transformações ocorridas no mundo do trabalho, das desigualdades sociais, as expressões da questão social se agravam, expressando-se através da fome, violência, desemprego, precárias condições de vida, dentre outros. Essa realidade rebate no cotidiano profissional do assistente social, pois este, conforme dito anteriormente, trabalha diretamente com as expressões da questão social.

Nos espaços de trabalho se presencia o aumento da demanda por serviços sociais, porém, em contrapartida há uma maior seletividade, falta de recursos materiais e humanos, e restrição de acesso da população a seus diretos por meio de critérios mais restritos, somente quem mais precisa é quem acaba sendo atendido, há uma seleção da parcela da população que mais precisa para ter acesso aos serviços da assistência social e, consequentemente, do trabalho do assistente social.

0 assistente social é o profissional que atua diretamente com as vítimas de violência e seus familiares, busca a efetivação dos direitos, a reflexão de que todos são sujeitos de direitos, protagonistas de sua história. Busca o fortalecimento dos laços familiares, para que a criança/adolescente que sofreu a violência não precise ser retirado de casa, garantir que esteja protegido em seu núcleo familiar. 0 profissional também realiza os encaminhamentos necessários aos outros membros do grupo familiar, como pedidos de inserção em creches, acesso à escola, programas sociais, atendimento psicossocial, inserção em cursos profissionalizantes, enfim, encaminhamentos e intervenções que buscam fortalecer essa família e "superar a situação de violência".

0 trabalho se realiza no dia a dia, no cotidiano dos usuários que fazem uso do serviço do CREAS. Nos casos de abuso sexual, o trabalho tem sempre o objetivo de proteger a criança e adolescente, unindo-se aos órgãos que fazem parte do sistema de garantia dos direitos e buscando o fortalecimento da própria rede de atendimento.

\section{o assistente social e a violência sexual intrafamiliar}

Ao atuar com as expressões da questão social em suas diversas manifestações, o assistente social lida diretamente com a violência sexual intrafamiliar contra crianças e adolescentes em diversos espaços sócio ocupacionais. Um destes espaços é o Centro de Referência Especializado de Assistência Social (CREAS)

O CREAS está inserido dentro da Política Nacional de Assistência Social (PNAS) que tem como proteções afiançadas a proteção social básica e proteção social especial, que é dividida em média e alta complexidade (Brasil, 2004, p.40), organizada em 2011 pelo Sistema Único de Assistência Social (SUAS), na Lei no 12.435/2011 (Brasil, 2011). Os serviços oferecidos pelos níveis de complexidade do SUAS são organizados pela Tipificação Nacional de Serviços Socioassistenciais, através da Resolução no 109, de 11 de Novembro de 2009 (Brasil, 2009), que os organiza em proteção social básica e proteção social especial de média e alta complexidade.

A proteção social básica tem como objetivo a prevenção, para que não ocorram situações de risco e destina-se a população que se encontra em situação de vulnerabilidade social e vínculos fragilizados. Os serviços da proteção social básica são ofertados preferencialmente pelo Centro de Referência de Assistência Social (CRAS), devendo abranger os serviços de "a) Serviço de Proteção e 
Atendimento Integral à Família (PAIF); b) Serviço de Convivência e Fortalecimento de Vínculos; c) Serviço de Proteção Social Básica no domicílio para pessoas com deficiência e idosas (Brasil, 2009, p 3)."

A proteção social especial destina-se às famílias e indivíduos que se encontrem em situação de risco ou violência. São serviços que requerem acompanhamento e atenção especial, pois são casos em que houve violação de direitos e estão ligados com o sistema de garantias de direitos, Poder Judiciário, Ministério Público bem como outros órgãos do executivo.

$\mathrm{Na}$ média complexidade são oferecidos serviços e atendimentos às famílias e indivíduos com direitos violados, cujos vínculos familiares e comunitários não foram rompidos, como no caso da violência sexual contra crianças e adolescentes, devido ser esta a modalidade da política de assistência social que atende às vítimas desta violação de direitos que é a violência sexual. $\mathrm{Na}$ alta complexidade são oferecidos os serviços de proteção integral para famílias e indivíduos que se encontram fora do núcleo familiar, ou seja, quando os vínculos familiares e comunitários foram rompidos.

O CREAS está inserido na proteção social especial de média complexidade, que conforme descrito anteriormente, destina-se às famílias e indivíduos que tiveram seus direitos violados, ou seja, quando ocorreu a violência, mas os vínculos não foram rompidos.

Assim, inserido no nível de Proteção Social Especial de Média Complexidade a gestão, como também os serviços oferecidos pelo CREAS são de responsabilidade do poder público local de onde está localizado. Os serviços oferecidos não podem sofrer interrupções, devido à gravidade de violação de direitos que são atendidas no local.

Dentre os serviços que são oferecidos encontramos o Serviço de Proteção e Atendimento Especializado a Famílias e Indivíduos (PAEFI), que se destina ao atendimento de famílias em que se apresenta a violação de direitos ou ameaça. Através do PAEFI é que são atendidos os casos de violência sexual, bem como de crianças e adolescentes que foram vítimas de violência sexual intrafamiliar.

Nestes casos, o trabalho do assistente social compreende o acompanhamento total do caso, com encaminhamentos aos diversos órgãos, conforme desenrolar do atendimento. 0 profissional do Serviço Social precisa ter a dimensão de todo o contexto, conteúdos de denúncia, procedência e as circunstâncias motivadoras da mesma e seu grau de gravidade. 0 profissional precisa ter cuidado para não revitimizar a criança/adolescente.

Por envolver a criança e o adolescente, a maioria dos casos atendidos pelo assistente social no CREAS é encaminhado pelo Conselho Tutelar, sempre em paralelo com a denúncia na Delegacia de Defesa da Mulher (DDM); os usuários dos casos que chegam sem a denúncia neste órgão são orientados a fazer a mesma e acionar o Conselho. Alguns casos são encaminhados respectivamente pelo conselho e pela DDM, chegando ao CREAS com os dois encaminhamentos, mas podem ser encaminhados por outros órgãos de proteção e atendimento e também por demanda espontânea.

$\mathrm{Na}$ pesquisa realizada foi possível perceber que a articulação entre os órgãos que compõem o Sistema de Garantia dos Direitos da Criança e do Adolescente é imprescindível para a efetivação do trabalho e atendimento dessas vítimas e o quanto é importante que estes estejam articulados para assegurar que estas crianças e adolescentes não sejam expostos novamente a situações de violação de direitos, direitos estes que devem ser garantidos pelo poder público, sociedade, família e Estado, conforme preconiza o ECA em seu artigo 4을 onde todos têm o dever de garantir e assegurar seus direitos fundamentais.

Muitas vezes, após a denúncia e essas crianças e adolescentes passarem por atendimento, estas podem ser vitimizadas novamente dentro do lar, no qual a família pode não acreditar no abuso e culpar a vítima pela saída do agressor do lar.

Assim, percebemos que mesmo após a denúncia, em muitos casos, as crianças e adolescentes vítimas desse tipo de violência acabam sofrendo pressão por parte da família, sendo culpabilizados pela denúncia e quebra da "harmonia" que existia dentro do lar, considerando-a culpada até mesmo pelo abuso.

As crianças e adolescentes, bem como suas famílias, passam na maioria das vezes por 
atendimento psicossocial, inserção em programas sociais e de fortalecimentos de vínculos, bem como em grupos desenvolvidos dentro e fora do espaço do CREAS. Dependendo da idade da vítima, esta também é inserida em cursos profissionalizantes, bem como seus familiares, com intuito de fortalecer essa família, para que a violência não ocorra.

Em alguns casos não é possível realizar o atendimento, alguns dos motivos são: alegação da família que a vítima já não se lembra do que aconteceu, negação da família em receber o atendimento, mudança de endereço e de cidade, a própria vítima não querer receber o atendimento, retirada da denúncia, dentre outros fatos.

Aos familiares da vítima também é oferecido o atendimento psicossocial, bem como os serviços que o CREAS realiza e encaminhamentos, mas nem sempre é possível atingir a todos.

Com o agressor não é realizado nenhum projeto ou atendimento específico, salvo em situações em que o agressor ainda resida no mesmo espaço em que a criança e o adolescente vive (uma triste realidade, pois com isso a criança e o adolescente está exposto à violência, tendo um convívio diário com o mesmo). Neste caso, o atendimento é realizado se o mesmo aceitar a intervenção, o que é muito raro, além de poucos locais oferecerem este tipo de atendimento. Uma pesquisa realizada em 2007, coordenada por Toneli (2007) demostrou que no Brasil foram encontrados somente dois serviços de atendimento para homens autores de agressão:

O Brasil vive uma situação grave no quesito dos serviços de atendimento a homens autores de agressão (tanto doméstica quanto sexual) visto que de todas as capitais brasileiras, apenas no Rio de Janeiro foi possível identificar programas de atenção a esta demanda, com algum destaque e consistência. Estes programas são distintos e desvinculados de qualquer iniciativa governamental, estadual ou municipal. (Toneli, 2007, p. 110).

Mesmo com todo o atendimento realizado pelo assistente social e equipe do CREAS corre-se o risco de alguns casos voltarem, com a mesma ou outras situações de violência. Um dos fatores é devido à criança ou adolescente ainda residir com o agressor, quando não houve o flagrante; há uma morosidade no inquérito e julgamento do agressor. Vale destacar que essas vítimas podem sofrer novamente a violência por outros membros da família, como já aconteceu em casos atendidos no CREAS, onde os mesmos voltam a ser atendidos ou não, pelo fato da violência ocorrer no âmbito do lar e a família querer esconder que houve a revitimização.

0 assistente social vai acompanhar o caso desde o momento em que chega ao CREAS até seu desligamento (encerramento), acompanha-o em sua totalidade, respeitando o que a família permite demonstrar durante o atendimento e acolhendo suas demandas. Realiza as orientações e os encaminhamentos aos demais órgãos de atendimento e que fazem parte da rede, em alguns casos executa seu trabalho junto com o psicólogo.

Ao constatar que a criança e o adolescente ainda pode estar em risco, exposto a situações de violência, o profissional deve acionar o sistema de garantia dos direitos, em primeiro lugar, o Conselho Tutelar, visto ser este o órgão encarregado de zelar pela efetivação dos direitos das crianças e adolescentes.

0 atendimento, acompanhamento desses casos pelo CREAS, e consequentemente pelo assistente social não tem um prazo definido de duração. Dos 19 casos pesquisados por Bezerra (2013), 3 ainda estavam sendo acompanhados, recebendo o atendimento. Nos outros casos que já foram encerrados, o atendimento durou de cinco meses a um ano e meio.

As profissionais que participaram da pesquisa destacaram o fator de a violência ser multicausal, sendo que somente uma área não é capaz de explicá-la e fazer as intervenções necessárias. É preciso que se estabeleça uma relação entre os diversos profissionais que fazem parte da rede de atendimento para a realização de um trabalho que seja efetivo e gere resultados positivos na vida de seus usuários. Profissionais que pensem a questão da violência como um todo, um fator que tem diversas causas e consequências na vida das pessoas que as vivenciam.

Assim, cabe ao profissional estar atento a tudo que o atendimento pode revelar, pois a violência sexual pode ser o primeiro sinal de que outras situações de violência estejam ocorrendo, bem como por necessidades que a família esteja passando, enfrentando situações de risco aos 
direitos inerentes à vida humana e desenvolvimento de seus filhos. É de fundamental importância que o assistente social esteja sempre atualizado, detendo o conhecimento das legislações pertinentes e serviços que possam ser oferecidos, bem como o cuidado para não revitimizar essas crianças e adolescentes.

\section{Considerações finais}

0 trabalho profissional do assistente social junto às crianças e adolescentes vítimas de violência sexual intrafamiliar deve ser livre de préconceitos e julgamentos, sem culpabilizar a família e a própria vítima pela situação de violência. Deve ser uma atuação capaz de obter uma relação de diálogo com a família, a fim de refletir sobre a violência ocorrida e procurar melhores maneiras de enfrentamento dessa situação, com alternativas que busquem 0 fortalecimento dos vínculos familiares e a proteção dessas crianças e adolescentes.

A atuação do profissional não pode ser feita de forma isolada e sem apoio, há a necessidade de compartilhamentos, uma vez que o fenômeno da violência é multidisciplinar e intersetorial e exige conhecimentos e intervenções feitas em rede nas diversas áreas, com objetivo de proteção dessas vítimas e para que não sejam revitimizadas e expostas a novas situações de violência.

A partir da escuta, da relação que se estabelece com a família e a própria vítima, é que o assistente social vai basear, planejar sua intervenção, através do atendimento, orientações e encaminhamentos à rede assistencial e de atendimento. 0 vínculo estabelecido entre o profissional, a vítima e sua família torna-se um ponto fundamental para sua intervenção no caso.

Verifica-se que mesmo com as legislações existentes, como o próprio Estatuto da Criança e do Adolescente, que visam à proteção integral, muitas de nossas crianças e adolescentes estão expostas às situações de violência, ocorridas muitas vezes no silêncio do lar, tendo no seio familiar a maior forma de violência a que poderiam ser submetidos, em vez de proteção, vivem no medo.

Infelizmente, podemos perceber que a violência sexual intrafamiliar está presente em muitos lares, independentemente de raça, cor, ou posição social, mas é nas camadas mais pobres da população que ela ganha os "holofotes", os casos vêm a público e são denunciados e divulgados pela mídia com mais facilidade. Nas classes mais altas, os casos de violência sexual são escondidos, envolvidos em um pacto de silêncio e muitas vezes encobertos, mesmo quando ocorre a denúncia, ficando longe da visão pública.

Assim, torna-se necessário chamar a atenção da sociedade sobre a violência sexual, mostrar que todos os dias crianças e adolescentes são vítimas desta violação. É preciso lutar pelos direitos da infância e adolescência, para que estes possam ter seu desenvolvimento garantido, livres de toda e qualquer forma de violência ou violação de seus direitos. 


\section{Referencias}

Bezerra, M. S. (2013). Por de trás daquelas portas: a violência sexual intrafamiliar contra crianças e adolescentes e o trabalho profissional do assistente social. 101 fls. Trabalho de Conclusão de Curso (Bacharel em Serviço Social) - Faculdade de Ciências Humanas e Sociais, Universidade Estadual Paulista "Júlio de Mesquita Filho", Franca.

Brasil. (2004). Política Nacional de Assistência Social. São Paulo: Cortez.

- (2009). Ministério do Desenvolvimento Social e Combate à fome. Conselho Nacional de Assistência Social. Resolução no 109 de 11 de novembro de 2009. Aprova a Tipificação Nacional de Serviços Socioassistenciais. Diário Oficial da União, Brasília, DF, 25 nov. 2009. Seção 1. Acesso em 16 de janeiro de 2017 de http://www.mds.gov.br/cnas/viiiconferencianacional/manualorientador/legislacao_resolucao-cnas-109-2009.pdf/download.

- (2011). Lei $\mathrm{n}^{\circ}$ 12.435, de 6 de julho de 2011. Altera a Lei no 8.742, de 7 de dezembro de 1993, que dispõe sobre a organização da Assistência Social. Diário Oficial da União, Brasília, DF, 7 jul. 2011. $\begin{array}{lllllll}\text { Acesso } & \text { em } & 9 & \text { de } & \text { março } & \text { de } & 2019\end{array}$ http://www.planalto.gov.br/ccivil_03/_Ato20112014/2011/Lei/L12435.htm.

- (2015). Estatuto da criança e do adolescente. Brasília, DF: Secretaria de Direitos Humanos da presidência da República.

- (2017) Ministério dos Direitos Humanos. Secretaria Especial de Direitos Humanos. Relatório Digital Balanço Anual 2017. Brasília, DF. Acesso em 31 de julho de 2018 de http://www.mdh.gov.br/informacao-ao-cidadao/ouvidoria/dados-disque100/relatorio-balancodigital.pdf/view.

Bueno, S. \& Lima, R.S. (coord.) (2019). Anuário Brasileiro de Segurança Pública. São Paulo, SP: Fórum Brasileiro de Segurança Pública. Acesso em 12 de setembro de 2019 de http://www.forumseguranca.org.br/publicacoes/13-anuario-brasileiro-de-seguranca-publica/.

Childhood - Instituto WCF - Brasil. (2019). A violência sexual infantil no Brasil: Entenda o cenário da violência sexual contra crianças e adolescentes no Brasil e saiba como preveni-la. Acesso em 19 de agosto de 2020 de https://www.childhood.org.br/a-violencia-sexual-infantil-no-brasil.

Gabel, M. (1997) Algumas observações preliminares. In: Gabel, M. (org.). Crianças vítimas de abuso sexual. São Paulo: Summus.

Graciani, M. S. S. (2013). Crianças e adolescentes têm direitos: conheça o Sistema de Garantia de Direitos e saiba como participar. São Paulo, SP: CONDECA: Manufatura de ideias.

Iamamoto, M. V. (2012). O Serviço Social na Contemporaneidade: trabalho e formação profissional. $22^{\mathrm{a}} \mathrm{ed}$. São Paulo: Cortez.

KosiK, K. (1976). Dialética do concreto. Rio de Janeiro: Paz e Terra.

Piana. M.C. \& Bezerra, M.S. (2019). Marcas na infância: o poder do adulto sobre a criança e a violência sexual. Revista Libertas, Juiz de Fora, 19(1) 200-212. DOI 10.34019/1980-8518.2019.v19.27782. $\begin{array}{llllll}\text { Acesso } & \text { em12 } & \text { de } & \text { setembro } & \text { de } & 2019\end{array}$ https://periodicos.ufjf.br/index.php/libertas/article/view/27782/18980.

Santos, B. R. \& Ippolito, R. (2009) Guia de referência: construindo uma cultura de prevenção à violência sexual. São Paulo: Childhood - Instituto WCF - Brasil: Prefeitura da Cidade de São Paulo: Secretaria de Educação.

Toneli, M. J. F. (2007). Violência sexual e saúde mental: análise dos programas de atendimento a homens autores de violência sexual. Relatório final de pesquisa. Universidade Federal de Santa Catarina. Florianópolis, Brasil. 